\title{
Cursing \\ EFFECTIVENESS OF A STRUCTURED TEACHING PROGRAMME ON KNOWLEDGE REGARDING SKILLED BIRTH ATTENDANTS
}

\section{Ms. Varsha \\ Gayke*}

Dr. Rajni Udeniya
M.Sc. Nursing final year, Community Health Nursing, SAIMS College of Nursing Indore (M.P.). ${ }^{*}$ Corresponding Author

ABSTRACT

Vice-Principle \& H.O.D. of Community Health Nursing SAIMS College of Nursing Indore (M.P.). important to conduct a pre-experimental study on Skilled Birth Attendant among nursing student. The main population consist of nursing students, sample size are 60 nursing students, was selected by using Non-probability convenient sampling technique. A demographic variable was used. Pre interventional knowledge level was assessed by self-structured knowledge questionnaire. The data collected was analysed by using descriptive and inferential statistics. The average (Mean \pm Standard Deviation) knowledge scoring in pre-test to measuring the pre-existed knowledge about skilled birth attendant found to be 10.40 with Standard Deviation 4.54. And post interventional knowledge score are 23.85 is Standard Deviation4.11.Standard error are $0.499 \&$ calculated't' value is 15.5307 at df 59 . The p value was 0.0001 (significant) which clearly show that structured teaching programme was very effective in increasing the knowledge of Nursing Students.

\section{KEYWORDS : Skilled Birth Attendant, Structured Teaching Programme, Nursing Students.}

\section{INTRODUCTION :}

As per the World Health Organization (WHO) skilled birth attendant (SBAs) are certify wellbeing experts. The term skilled birth attendance has been defined as the process by which a woman is provided with adequate care during labour, delivery and the early post-partum period. An increase in the proportion of deliveries with skilled attendance has been identified as an important approach to reduce maternal mortality and morbidity in developing maternal mortality proportion by seventy countries. Skilled attendance at conveyance is a progress to diminish the five percent somewhere in the range of 1990 and 2015.

Surya Bali, Venkatashiva B Reddy (2018), conducted the study on "Evaluation of competency and skills of skilled birth attendants in Madhya Pradesh, Central India". They mainly assessed SBAs capability in Madhya Pradesh utilizing organized assessment devices. It had been a cross sectional investigation, which assessed that among 335 skilled births attendant $41.8 \%$ were auxiliary nurse midwife, $47.8 \%$ were staff nurture, and $10.4 \%$ were woman wellbeing guests. While gathering all supplier and information test variants, SBAs was right on $75.4 \%$ of the inquiries. By theme, results extended from $77.9 \%$ right for the administration of typical pregnancy and labor to $70.2 \%$ right for intranatal care. The current investigation discovered huge varieties in information and ability competency scores of the SBAs. They proposed that there is a basic need to improve the preparation nature of expertise birth orderlies.

\section{OBJECTIVE -}

1. To assess the pre- test knowledge regarding Skilled Birth Attendant among nursing student of selected nursing institutes of Indore city.

2. To assess the effectiveness of structured teaching programme on knowledge regarding skilled birth attendant among Nursing student of selected nursing institutes of Indore city.

3. To find out the association between pre-test knowledge score regarding with selected demographic variables.

\section{HYPOTHESIS -}

1. $\mathbf{R H}_{01-}$ There will be no significant difference between per-test and post-test knowledge score regarding Skilled Birth Attendant among nursing student of selected nursing institutes of Indore city.

2. $\mathbf{R H}_{1}$ - There will be mean post-test knowledge scores of the Nursing student regarding Skilled Birth Attendant is significantly higher than their mean pre-test knowledge scores.

3. $\mathbf{R H}_{02}-$ There will be no significant association between mean pre tests knowledge score of Nursing student and selected sociodemographic variables.

4. $\mathbf{R H}_{2}-$ There will be significant association between mean pre tests knowledge score of Nursing student with selected sociodemographic variables.

\section{METHODOLOGY:-}

In the present study quantitative evaluative approach was used to assess the effectiveness of structured teaching programme on knowledge regarding skilled birth attendant among the nursing students . The researcher adopted a pre - experimental (one group pretest post - research design). 60 nursing students from selected college of Indore, through a Non probability convenient sampling technique. A self- structured Multiple Choice Questionnaire was prepared to assess the knowledge of nursing students followed by the structured questionnaire.

\section{RESULT :-}

- The analysis clearly shows that $20(33.3 \%)$ out of 60 had poor knowledge, 34 (56.1\%) had average knowledge, 05(7.3\%) had good knowledge and 1(3.3\%) had excellent knowledge with standard mean equal to 10.54 and standard deviation 4.54

- After providing intervention of structured teaching progamme, the statistical analysis reported that the $30(50 \%)$ out of 60 had good knowledge, $25(41.7 \%)$ had excellent knowledge, $05(8.3 \%)$ had average knowledge. The post test mean found to be 23.85 with standard deviation 4.1 .

- It is concluded statistically that the administered structured teaching program on knowledge among Nursing students regarding skilled birth attendant found to be very effective which can also be examined by observing figures.

Table No.1 Frequency And Percentage Distribution Of Selected nursing Students. $(\mathrm{n}=\mathbf{6 0})$

\begin{tabular}{|c|c|c|}
\hline Characteristics of samples & Frequency $(\mathrm{N})$ & Percentage (\%) \\
\hline \multicolumn{3}{|c|}{ Age of Nursing Students } \\
\hline 19-20 Year & 20 & 33.3 \\
\hline 21-22 Year & 23 & 38.4 \\
\hline 23-24 Year & 14 & 23.3 \\
\hline Above 24 Year & 03 & 05 \\
\hline \multicolumn{3}{|c|}{ Gender of Nursing Students } \\
\hline Male & 17 & 28.3 \\
\hline Female & 43 & 71.7 \\
\hline \multicolumn{3}{|c|}{ Educational Qualification of Nursing Students } \\
\hline G.N.M.3 ${ }^{\text {rd }}$ Year & 15 & 25 \\
\hline B.Sc. Nursing $4^{\text {th }}$ Year & 45 & 75 \\
\hline \multicolumn{3}{|c|}{ Gender of Nursing Students } \\
\hline Male & 17 & 28.3 \\
\hline Female & 43 & 71.7 \\
\hline \multicolumn{3}{|c|}{ Educational Qualification of Nursing Students } \\
\hline Yes & 22 & 36.7 \\
\hline No & 38 & 63.3 \\
\hline \multicolumn{3}{|c|}{ Source of Knowledge of Nursing Students } \\
\hline Mass Media / Print Media & 02 & 5.2 \\
\hline Educational Institute & 32 & 84.3 \\
\hline Seminar/ Workshop & 01 & 2.6 \\
\hline Health Team Member & 03 & 7.9 \\
\hline Total & 38 & 100 \\
\hline
\end{tabular}


Comparison Of The Pre-test And Post- Test Knowledge Score

Skilled Birth Attendant Among Nursing Students $(\mathrm{n}=\mathbf{6 0})$

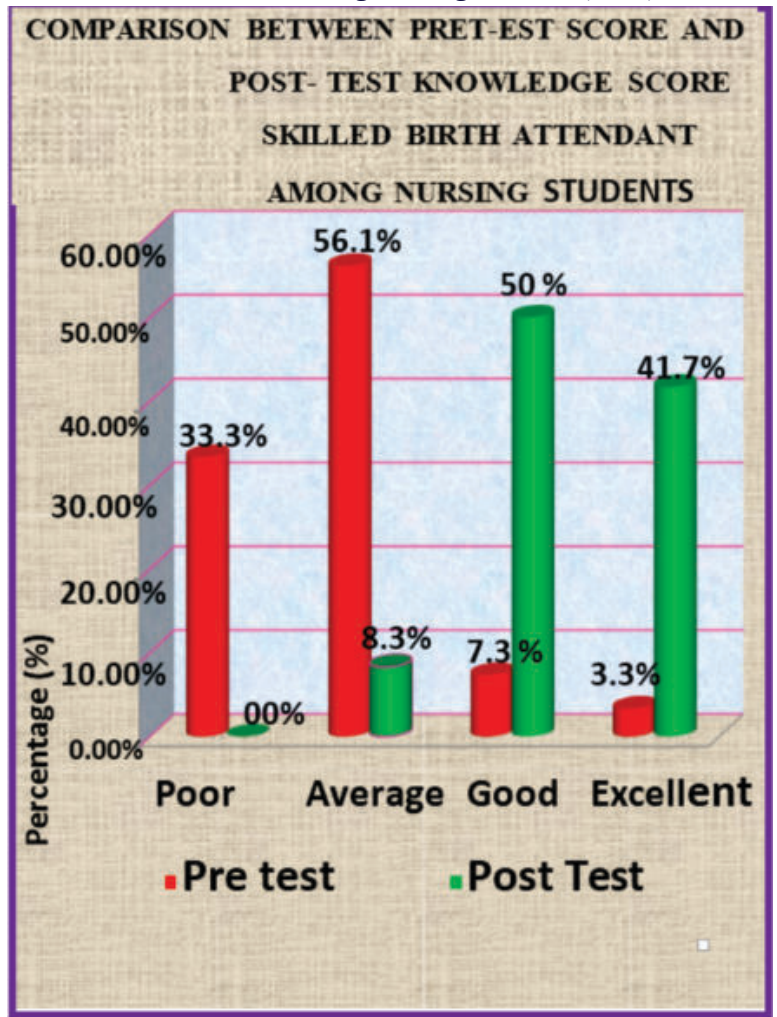

Figure - Column diagram showing the comparison in knowledge levels among Nursing before (pre-test) and after administration (posttest) of structured teaching programme.

\section{LIMITATION}

- The study is limited to the samples admitted in the selected nursing institute of Indore city.

- This study is limited to only those who are available at the time of data collection.

- This study is limited to only 60 nursing students.

- This study is limited to nursing students whose data can be available through goggle form application.

\section{CONCLUSION:-}

The main conclusion drawn from this present study was the level of knowledge regarding the skilled birth attendant among the nursing students through structured teaching programme found to be highly significant in providing knowledge among the Nursing Students .

\section{REFERENCE}

1. Adetoro Adegoke, Bettina Utz, Sia E Msuya, Nynke Van Broek (2012), Skilled Birth Attendants: Who is Who? A Descriptive Study of Definitions and Roles from Nine Sub Saharan African Countries, PLOS ONE, 7(7): e40220.

2. Ankit Anand (2017), Utilization Of Skilled Birth Attendant In South Asian Region: Indian Journal Of Public Health, Volume 6, Issue 7, Page Number -69-70

3. Gizachew Sime Ayele, Abulie Takele Melku (2019), Utilization of skilled birth attendant at birth and associated factors among women who gave birth in the last $24 \square$ months preceding the survey in Gura Dhamole Woreda, Bale zone, southeast Ethiopia, BMC Public Health, 19: 1501.. doi: 10.1186/s12889-019-7818-6

4. Harvey SA,Ayabaca P, Djibrina S (2017), Skilled birth attendant competence: an initial assessment in four countries, and implications for the Safe Motherhood movement. Quality Assurance Project, University Research Co., Volume 21 , Issue 4, Page number 35-36.

5. Surya Bali, Venkatashiva B Reddy (2018), Evaluation of competency and skills of sskilled birth attendants in Madhya Pradesh, Central India, International Journal Of Public Health, Volume ss62, Issue 1, Page Number 61-64.

6. Susan A Jones, Betty Sam, Florenece Bull (2016), Strengthening pre-service training for skilled birth attendance - An evaluation of the maternal and child health aide training programme in Sierra Leone, Nursing Education Today, Volume 41 , Pages $24-$ 29 . 